Supplementary Information

\title{
Full-Color Emission in Multicomponent Metal-Organic Frameworks via Linker Installation
}

Guodong Han, ${ }^{\dagger, \S}$ Shenjie Wu, ${ }^{\dagger, \S}$ Kang Zhou, ${ }^{\dagger}$ Hai-Lun Xia, ${ }^{\dagger}$ Xiao-Yuan Liu, ${ }^{*},{ }^{\dagger}$ and Jing Li ${ }^{*},+, \dagger$

${ }^{\dagger}$ Hoffmann Institute of Advanced Materials, Shenzhen Polytechnic, 7098 Liuxian Blvd, Nanshan District, Shenzhen, 518055, P.R. China

$\$$ Department of Chemistry and Chemical Biology, Rutgers University, 123 Bevier Road, Piscataway, New Jersey 08854, United States

§These authors contributed equally.

Email: liuxiaoyuan1989@szpt.edu.cn

jingli@rutgers.edu 


\section{Chemicals}

Zirconium (IV) chloride $\left(\mathrm{ZrCl}_{4}\right.$, Alfa Aesar, 99.5\%), 2-aminoterephthalic acid $\left(\mathrm{NH}_{2}-\mathrm{BDC}\right.$, Acros Organics, 99\%), trifluoroacetic acid (Oakwood Chemical, 99\%) and 4methoxycarbonylphenylboronic acid (Sigma-Aldrich, >95\%) were purchased from the mentioned sources and used without further purification. 2,2'-dimethyl-4,4'biphenyldicarboxylate acid (Me 2 -BPDC) and 5',5'"'-(Buta-1,3-diyne-1,4-diyl)bis(([1,1':3',1"terphenyl]-4,4"-dicarboxylic acid)) were purchased from Jilin Chinese Academy of ScienceYanshen Technology Co., Ltd. 4,4'-(2H-benzo[d][1,2,3]triazole-4,7-diyl)bis(3methoxybenzoic acid) (BAMB), 4,4'-(5,6-dimethylbenzo[c][1,2,5]thiadiazole-4,7diyl)dibenzoic acid (MBTB), 4,4'-(benzo[c][1,2,5]thiadiazole-4,7-diyl)bis(3-methoxybenzoic acid) (BTMB), 4,4'-(benzo[c][1,2,5]selenadiazole-4,7-diyl)bis(3-methoxybenzoic acid) (BSMB), 4,4'-(naphtho[2,3-c][1,2,5]-thiadiazole-4,9-diyl)dibenzoic acid (NTB) and 4,4'(naphtho[2,3-c][1,2,5]selenadiazole-4,9-diyl)dibenzoic acid (NSB) were synthesized according to our previous work. ${ }^{1,2}$ All the other chemicals were obtained from the chemical supplies and used without further purification.

\section{Characterization}

Nuclear magnetic resonance (NMR) data was collected using 400 MHz JEOL JNM-ECZ400S. Powder X-ray diffraction (PXRD) patterns were measured using Bruker D8 Advance X-ray diffractometer with $\mathrm{Cu} \mathrm{K} \alpha$ radiation. Single crystal X-ray diffraction data were collected at 270 K on a Bruker D8 Venture diffractometer with graphite monochromated Ga K $\alpha$ radiation $(\lambda=$ $1.34139 \AA$ A). The photoluminescent spectra were recorded on FLS1000 spectrofluorometer (Edinburgh Instruments). The UV-vis spectra were recorded on Shimadzu UV-3600 
spectrophotometer. The quantum yield was measured using C9920-03 absolute quantum yield measurement system (Hamamatsu Photonics) with a $150 \mathrm{~W}$ xenon monochromatic light source and 3.3 inch integrating sphere. FTIR spectra were collected on IRTrace-100 spectrometer (SHIMADZU). Elementary analysis was recorded on Elementar Vario EL cube.

\section{Synthesis of NPF-300}

$23.3 \mathrm{mg} \quad \mathrm{ZrCl}_{4}, \quad 10 \mathrm{mg} \quad$ 5',5"'-(Buta-1,3-diyne-1,4-diyl)bis(([1,1':3',1"-terphenyl]-4,4"dicarboxylic acid)), $700 \mathrm{mg}$ benzoic acid and $3 \mathrm{~mL}$ DMF were added in a $5 \mathrm{~mL}$ via. The mixture was sonicated 5 minutes and then heated in a $120{ }^{\circ} \mathrm{C}$ oven for 3 days. After cooling down to room temperature, the light yellow crystals of NPF-300 were obtained by filtration $(13.3 \mathrm{mg}$, yield: $83.6 \%$ ). FTIR $\left(\mathrm{KBr}, \mathrm{cm}^{-1}\right) 1721,1661,1598,1548,1503,1394,1252,1180,1145,1092$, 1011, 899, 853, 810, 777, 711, 648. Anal. Calcd (\%) for NPF-300 (no metal): C, 64.8; H, 4.18\%. Found: C, 45.84; H, 6.23\%.

\section{Synthesis of NPF-300-L (L: BAMB, MBTB, BTMB, BSMB, NTB and NSB) ${ }^{3}$}

$60 \mathrm{mg}$ as-synthesized NPF-300 was added into $10 \mathrm{~mL}$ DMF containing $80 \mu \mathrm{mol} \mathrm{L}$, which was put in a preheated oven at $80^{\circ} \mathrm{C}$ for 24 hours. After cooling down to room temperature, the solvent was exchanged several times with fresh DMF until no fluorescent signal was detected in the supernatant.

For NPF-300-BAMB, 60.2 mg, yield: 82.6\%; FTIR (KBr, $\left.\mathrm{cm}^{-1}\right)$ 1721, 1661, 1598, 1548, 1503, 1394, 1252, 1180, 1145, 1092, 1011, 899, 853, 810, 777, 711, 648; Anal. Calcd (\%) (no metal): C, 66.50; H, 4.00; N, 2.12\%. Found: C, 63.62; H, 7.72; N, 11.02\%.

For NPF-300-MBTB, 58.6 mg, yield: 84.4\%; FTIR (KBr, $\left.\mathrm{cm}^{-1}\right)$ 1721, 1661, 1598, 1548, 1503, 1394, 1252, 1180, 1145, 1092, 1011, 899, 853, 810, 777, 711, 648; Anal. Calcd (\%) (no metal): 
C, 67.00; H, 3.86; N, 1.42\%. Found: C, 45.46; H, 6.09; N, 7.45\%.

For NPF-300-BTMB, $63.1 \mathrm{mg}$, yield: 89.7\%; FTIR $\left(\mathrm{KBr}, \mathrm{cm}^{-1}\right)$ 1721, 1661, 1598, 1548, 1503, 1394, 1252, 1180, 1145, 1092, 1011, 899, 853, 810, 777, 711, 648; Anal. Calcd (\%) (no metal):

C, 65.93; H, 3.90; N, 1.40\%. Found: C, 44.63; H, 5.94; N, 6.88\%.

For NPF-300-BSMB, 65.2 mg, yield: 91.0\%; FTIR (KBr, $\left.\mathrm{cm}^{-1}\right)$ 1721, 1661, 1598, 1548, 1503, 1394, 1252, 1180, 1145, 1092, 1011, 899, 853, 810, 777, 711, 648; Anal. Calcd (\%) (no metal): C, 64.40; H, 3.80; N, 1.36\%. Found: C, 67.46; H, 9.32; N, 10.60\%.

For NPF-300-NTB, 63.9 mg, yield: 91.3\%; FTIR (KBr, $\left.\mathrm{cm}^{-1}\right)$ 1721, 1661, 1598, 1548, 1503, 1394, 1252, 1180, 1145, 1092, 1011, 899, 853, 810, 777, 711, 648; Anal. Calcd (\%) (no metal): C, 67.47; H, 3.92; N, 1.40\%. Found: C, 45.22; H, 6.54; N, 6.48\%.

For NPF-300-NSB, 64.5 mg, yield: 90.4\%; FTIR (KBr, $\left.\mathrm{cm}^{-1}\right)$ 1721, 1661, 1598, 1548, 1503, 1394, 1252, 1180, 1145, 1092, 1011, 899, 853, 810, 777, 711, 648; Anal. Calcd (\%) (no metal): C, 65.88; H, 3.82; N, 1.37\%. Found: C, 46.48; H, 6.30; N, 6.18\%.

\section{Synthesis of $\mathrm{PCN}-700^{4}$}

$50 \mathrm{mg} \mathrm{Me}$-BPDC and $50 \mathrm{mg} \mathrm{ZrCl}_{4}$ were added into a $20 \mathrm{~mL}$ vial with $0.5 \mathrm{~mL}$ trifluoroacetic acid and $10 \mathrm{~mL}$ DMF. The mixture solution was heated in a $120{ }^{\circ} \mathrm{C}$ oven for 4 days. After cooling down to room temperature, the formed crystals were filtered and washed several times using DMF and hexane (58 mg, yield: 75.1\%). FTIR (KBr, $\left.\mathrm{cm}^{-1}\right)$ 1660, 1592, 1538, 1414, 1371, 1205, 1128, 913, 853, 779, 656; Anal. Calcd (\%) (no metal): C, 60.00; H, 5.00\%. Found: C, 40.21; H, 6.07\%.

\section{Synthesis of PCN-701- $\mathrm{NH}_{2}$}

$25 \mathrm{mg}$ as-synthesized PCN-700 was added into a $4 \mathrm{~mL}$ Pyrex vial with $1 \mathrm{~mL}$ DMF containing 
$30 \mathrm{mM} \mathrm{NH}_{2}$-BDC. The mixture was heated in an $80{ }^{\circ} \mathrm{C}$ oven for 24 hours. After cooling down to room temperature, the light yellow crystal was filtered and washed several times with DMF and hexane (23.8 mg, yield: 88.1\%). FTIR (KBr, $\left.\mathrm{cm}^{-1}\right)$ 1660, 1592, 1538, 1414, 1371, 1205, 1128, 913, 853, 779, 656; Anal. Calcd (\%) (no metal): C, 60.55; H, 4.83; N, 0.98\%. Found: C, $39.19 ; \mathrm{H}, 5.92 ; \mathrm{N}, 5.33 \%$.

\section{Synthesis of PCN-702-NTB}

$25 \mathrm{mg}$ as-synthesized PCN-700 was added into a $4 \mathrm{~mL}$ Pyrex vial with $1 \mathrm{~mL}$ DMF containing $30 \mathrm{mM}$ NTB. The mixture was heated in an $80^{\circ} \mathrm{C}$ oven for 24 hours. After cooling down to room temperature, the formed crystal was filtered and washed several times with DMF and hexane (30.4 mg, yield: 95.1\%). FTIR $\left(\mathrm{KBr}, \mathrm{cm}^{-1}\right)$ 1660, 1592, 1538, 1414, 1371, 1205, 1128, 913, 853, 779, 656; Anal. Calcd (\%) (no metal): C, 63.16; H, 4.66; N, 1.67\%. Found: C, 45.72; H, 6.58; N, 4.79\%.

\section{Synthesis of PCN-703 by sequential installation of $\mathrm{NH}_{2}-\mathrm{BDC}$ and $\mathrm{H}_{2}-\mathrm{NTDB}$}

$25 \mathrm{mg}$ as-synthesized PCN-701- $\mathrm{NH}_{2}$ was added into a $4 \mathrm{~mL}$ Pyrex vial with $1 \mathrm{~mL}$ DMF containing $0.40 \mathrm{mg}, 0.60 \mathrm{mg}$ and $2.0 \mathrm{mg} \mathrm{H}$-NTDB. The mixture was heated in an $80{ }^{\circ} \mathrm{C}$ oven for 24 hours. After cooling down to room temperature, the formed crystal was filtered and washed several times with DMF and hexane to get PCN-703-1, PCN-703-2 and PCN-703-3.

\section{Single-crystal X-ray diffraction analyses}

Single crystal of NPF-300-MBTB was mounted on MicroMesh (MiTeGen) with paraton oil. The data was collected on a 'Bruker D8 VENTURE Metaljet PHOTON II' diffactometer with $\mathrm{Cu} \mathrm{K \alpha}$ microfocus X-ray source. The crystals were kept at the $270 \mathrm{~K}$ during data collection. Using Olex $2^{5}$, the structures were solved with the ShelXT ${ }^{6}$ structure solution program using 
Intrinsic Phasing and refined with the ShelXL ${ }^{7}$ refinement package using Least Squares minimization. For the benzene ring of the MBTB ligand was disordered and all of the $\mathrm{C}$ atoms were refined using geometry restraints (SADI). Restraints were also used to refine anisotropic displacement parameters of all non-hydrogen atoms (SIMU). The disordered non-coordinated solvents were removed using the PLATON SQUEEZE program, subsequently a set of solventfree diffraction intensities was produced. In the structure NPF-300-MBTB, the formate and the MBTB ligands share the same coordinated site with partial occupancies (occupancy 0.618:0.382). Furtherly, the thiadiazole groups of the MBTB ligand is disordered over two positions (occupancy $0.5: 0.5$ ), while the methyl group in the MBTB ligand cannot be fixed because of the serious disorder. The refinement results are summarized in Table S1. Crystallographic data for the NPF-300-MBTB in CIF format have been deposited in the Cambridge Crystallographic Data Centre (CCDC) under deposition numbers CCDC-2109845 (NPF-300-MBTB), the data can be obtained free of charge via www.ccdc.cam.ac.uk/data_request/cif (or from the Cambridge Crystallographic Data Centre, 12 Union Road, Cambridge CB2 1EZ, U.K.)

\section{Digestion Procedure of MOFs for ${ }^{1} \mathrm{H}$ NMR measurement}

$15 \mathrm{mg}$ as-synthesized MOFs were washed three times using DMF and the collected solids in 5 $\mathrm{mL}$ vials were put into one $150{ }^{\circ} \mathrm{C}$ oven overnight. Then for NPF-300 series, the MOFs were added into $0.5 \mathrm{~mL}$ saturated $\mathrm{K}_{3} \mathrm{PO}_{4} \mathrm{D}_{2} \mathrm{O}$ solution and $1 \mathrm{~mL}$ DMSO- $d_{6}$, which was sonicated for 10 mins. The DMSO- $d_{6}$ phase was used for ${ }^{1} \mathrm{H}$ NMR measurement. For PCN-700 series, $50 \mathrm{ul}$ $12 \mathrm{M} \mathrm{HCl}$ was added into the vials, which were put into one $100{ }^{\circ} \mathrm{C}$ oven to dry for several hours. After cooling down to room temperature, $800 \mathrm{uL}$ DMSO- $d_{6}$ was added to dissolve the 
resulted organic linkers. After filtering, the solution of DMSO- $d_{6}$ containing linkers was used for the ${ }^{1} \mathrm{H}$ NMR measurement. 


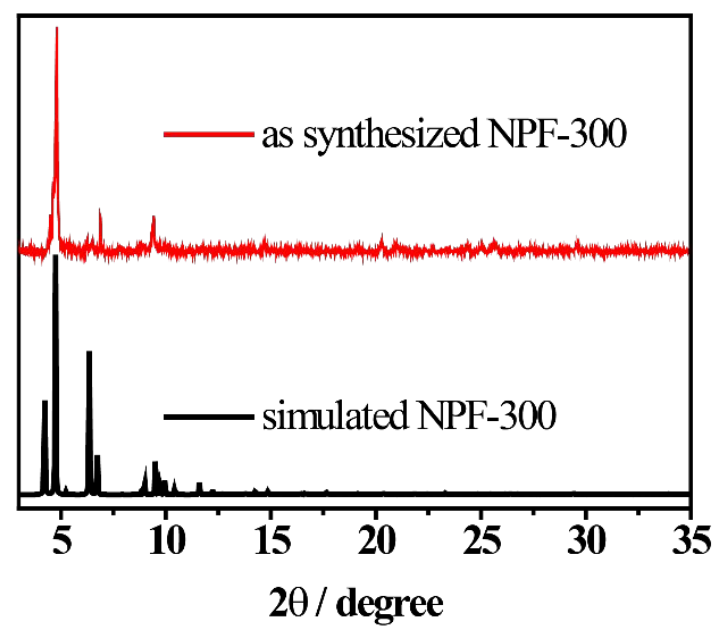

Figure S1. The PXRD patterns of simulated and as-synthesized NPF-300. 


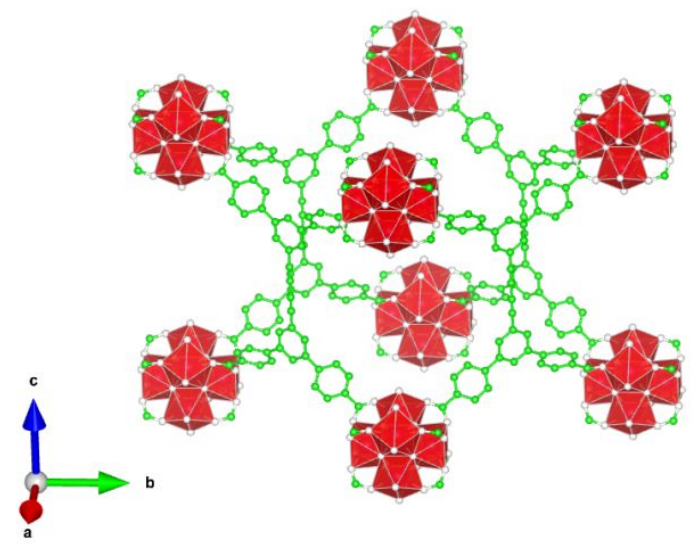

Figure S2. The single crystal structure of NPF-300. ${ }^{3}$ 


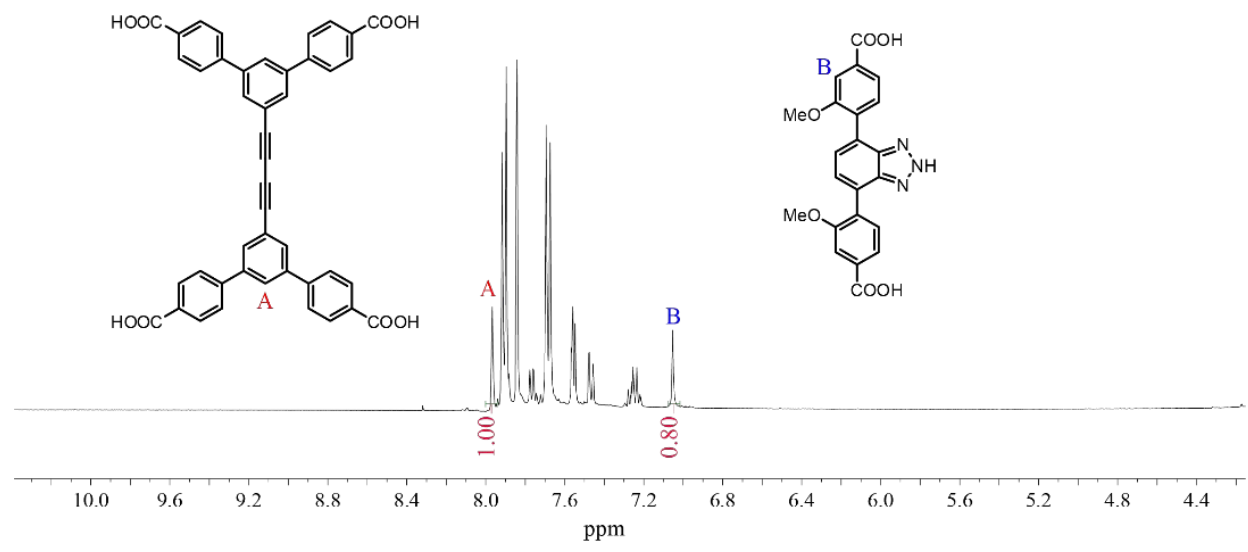

Figure S3. ${ }^{1} \mathrm{H}$ NMR spectrum of digested NPF-300-BAMB in DMSO- $d_{6}$. 


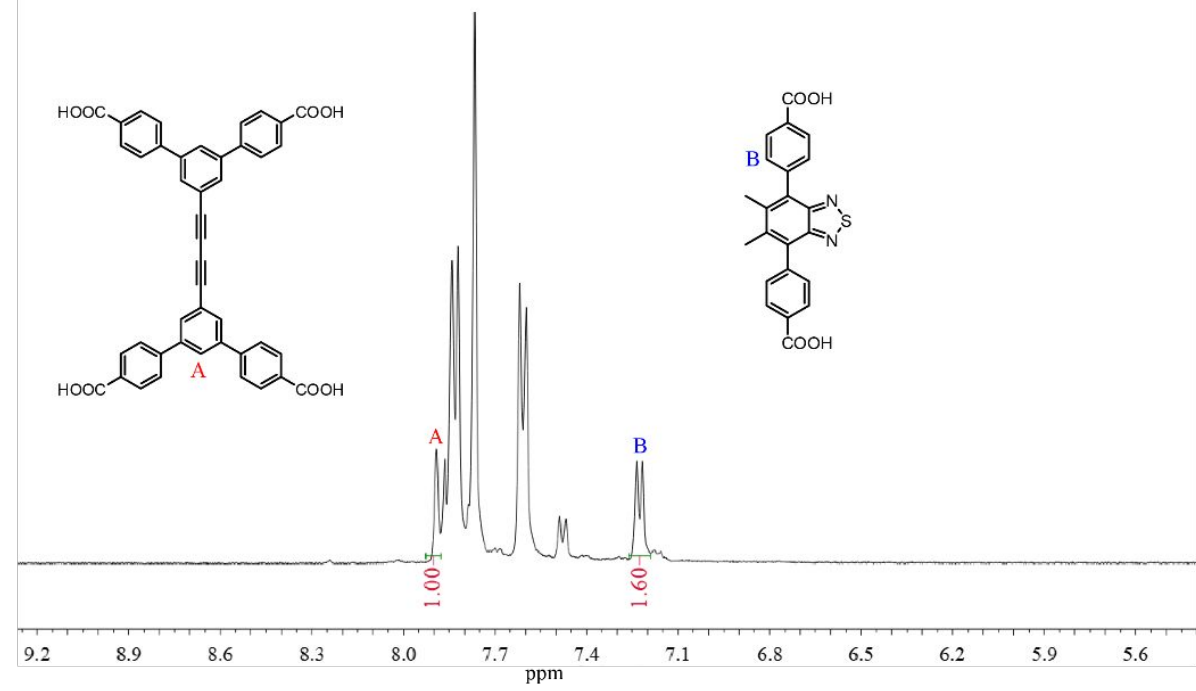

Figure S4. ${ }^{1} \mathrm{H}$ NMR spectrum of digested NPF-300-MBTB in DMSO- $d_{6}$. 


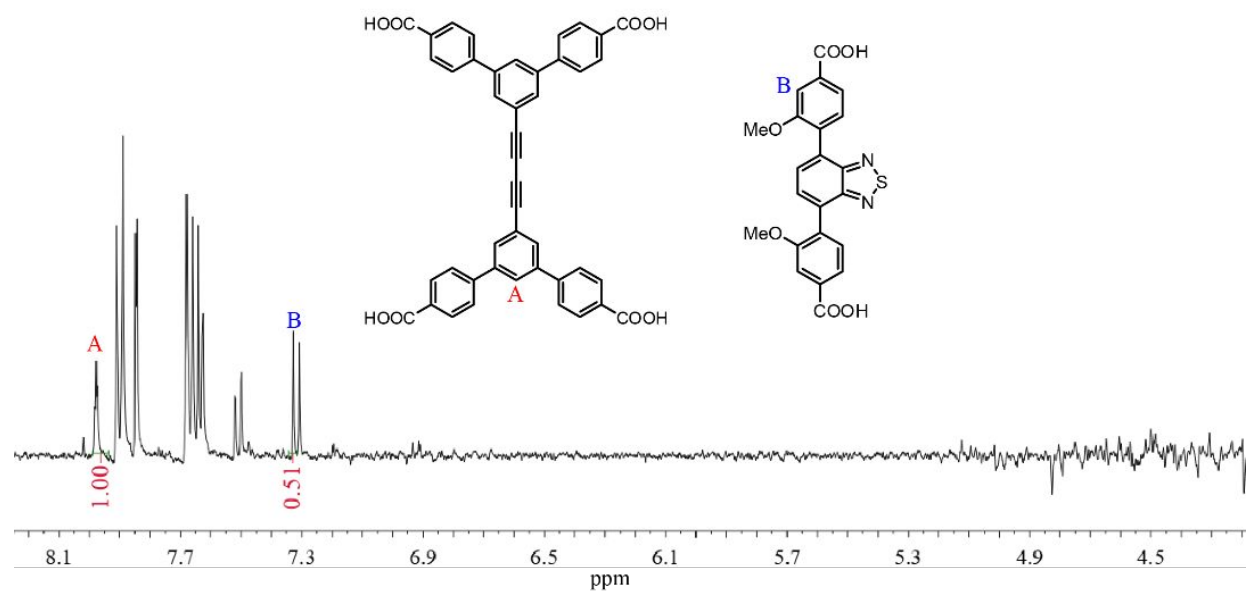

Figure S5. ${ }^{1} \mathrm{H}$ NMR spectrum of digested NPF-300-BTMB in DMSO- $d_{6}$. 


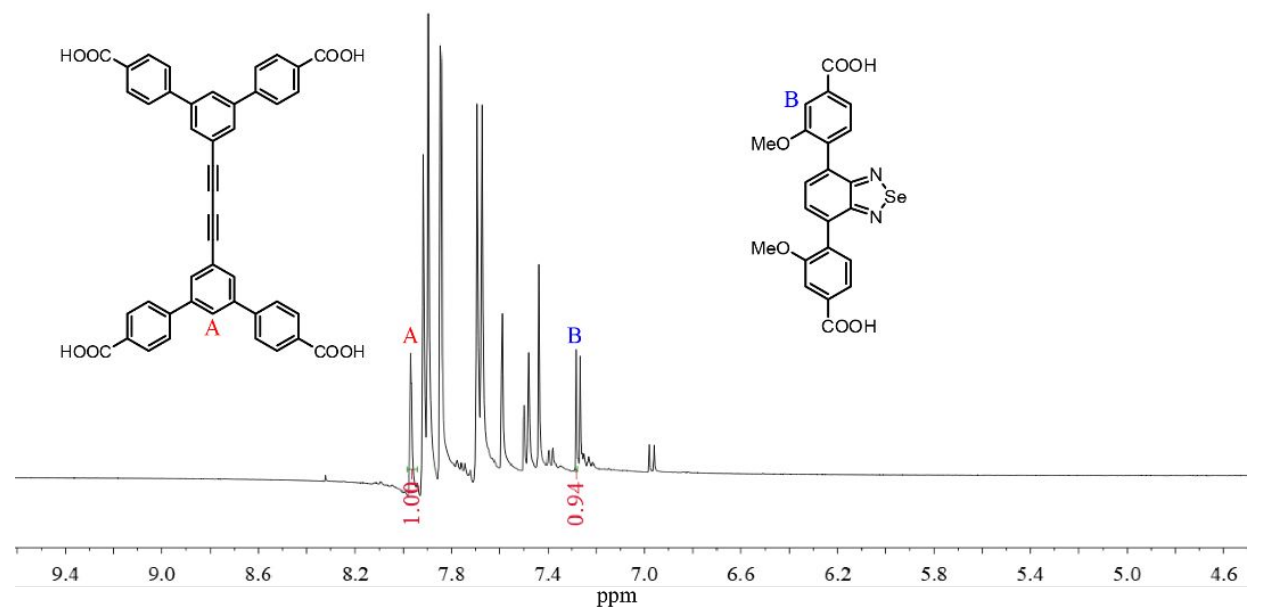

Figure S6. ${ }^{1} \mathrm{H}$ NMR spectrum of digested NPF-300-BSMB in DMSO- $d_{6}$. 


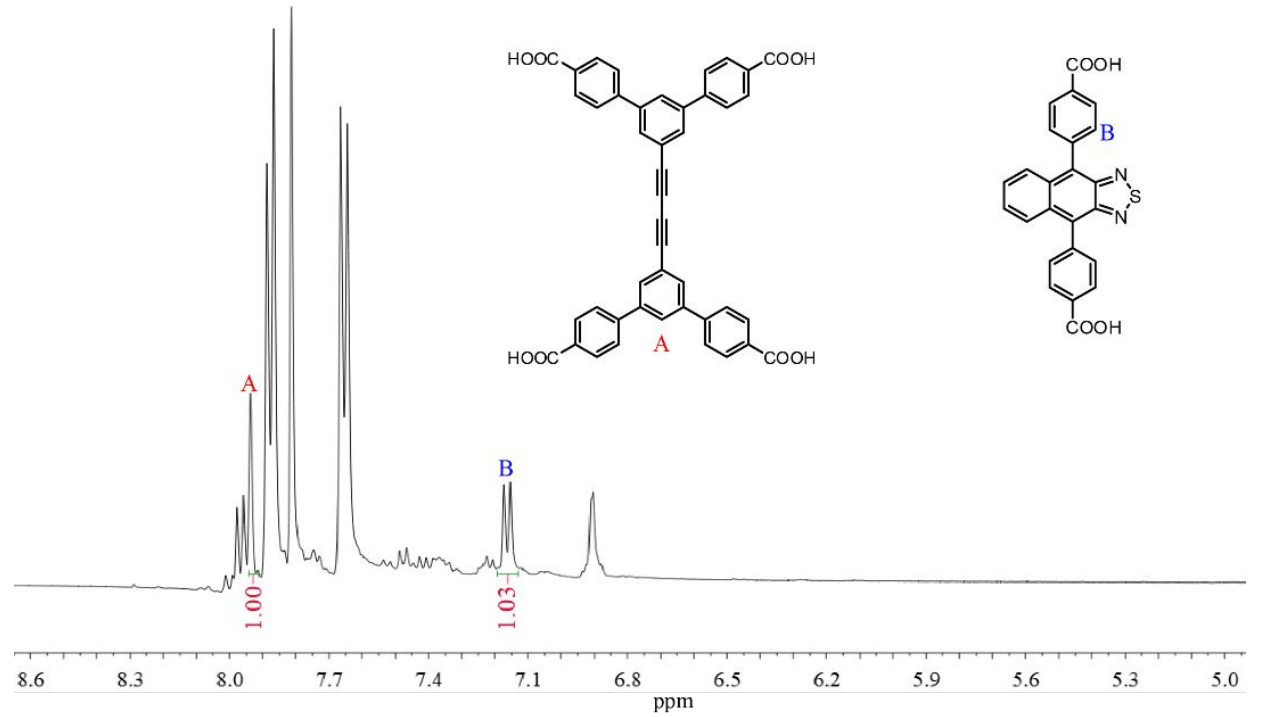

Figure S7. ${ }^{1} \mathrm{H}$ NMR spectrum of digested NPF-300-NTB in DMSO- $d_{6}$. 


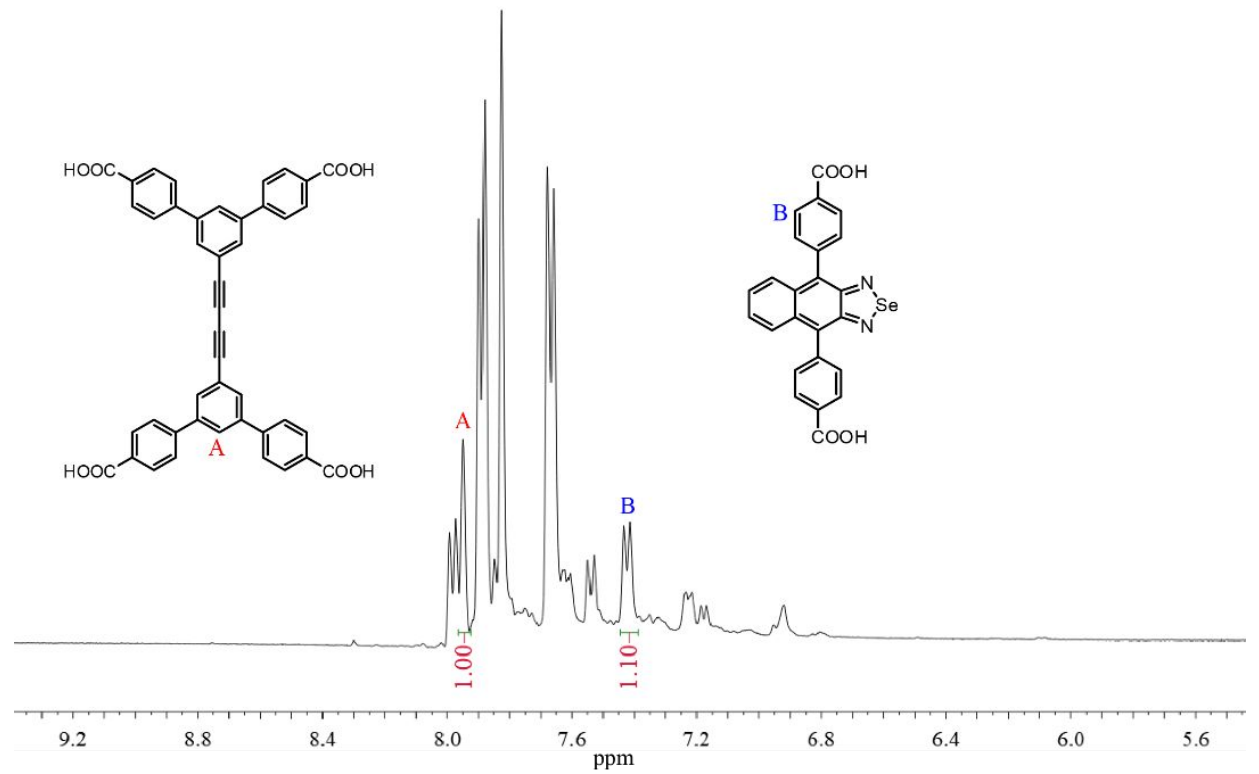

Figure S8. ${ }^{1} \mathrm{H}$ NMR spectrum of digested NPF-300-NSB in DMSO- $d_{6}$. 

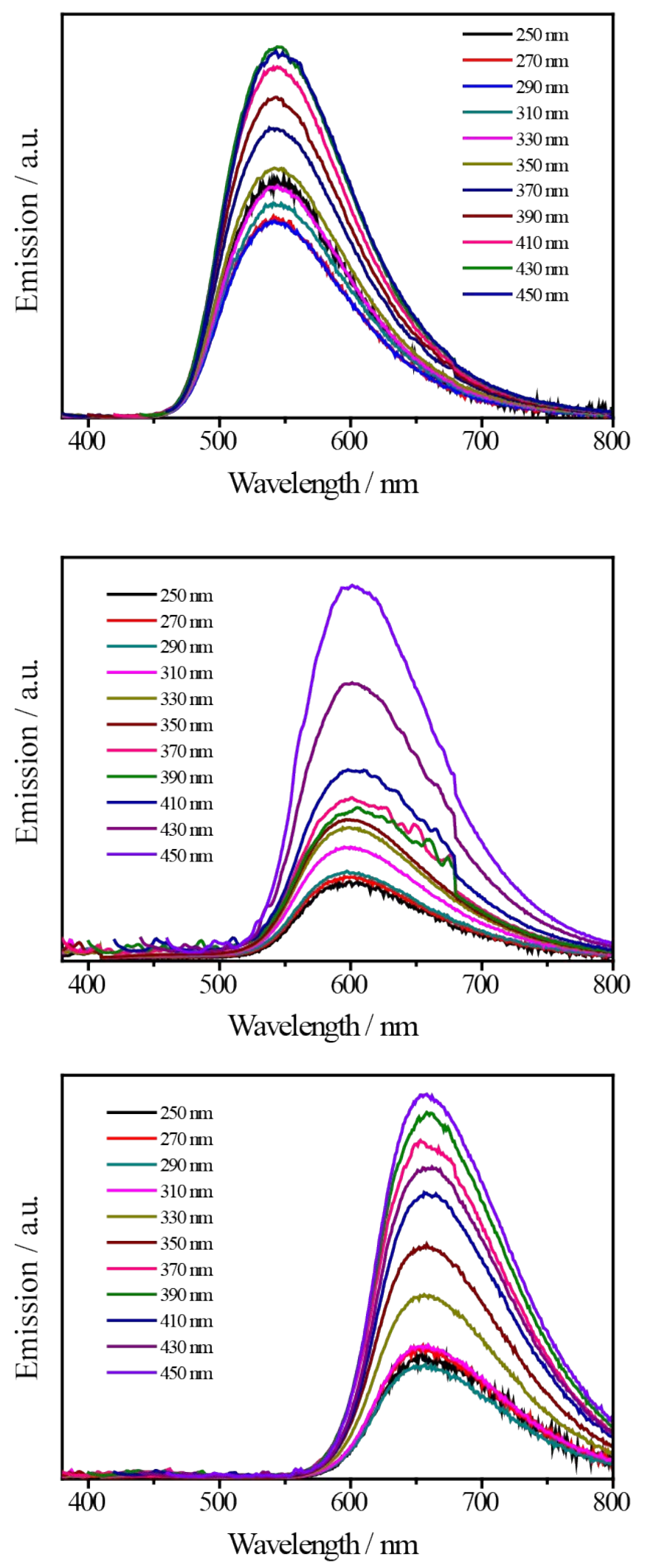

Figure S9. Solid-state photoluminescence spectra of NPF-300-BSMB, NPF-300-NTB and NPF-300-NSB under different excitation energies. 


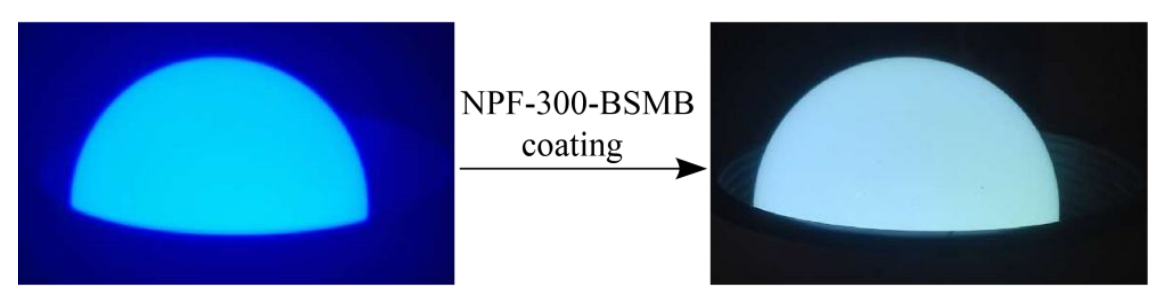

Figure S10. Photograph of a $450 \mathrm{~nm}$ blue light LED lamp when the power is turned on (left) and photograph of the LED lamp coated with NPR-300-BSMB when the power is turned on (right). 


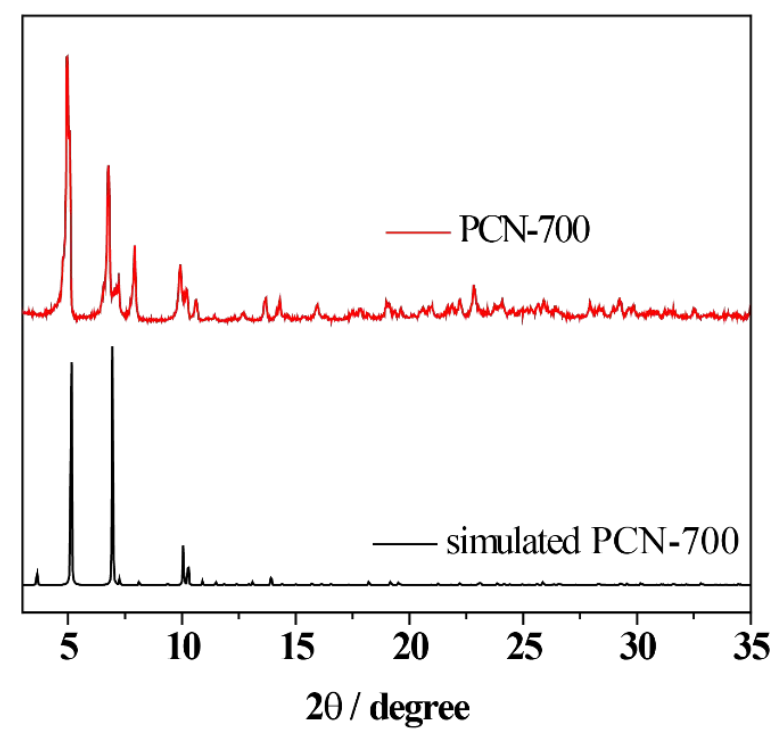

Figure S11. The PXRD patterns of simulated PCN-700 and as-synthesized PCN-700. 


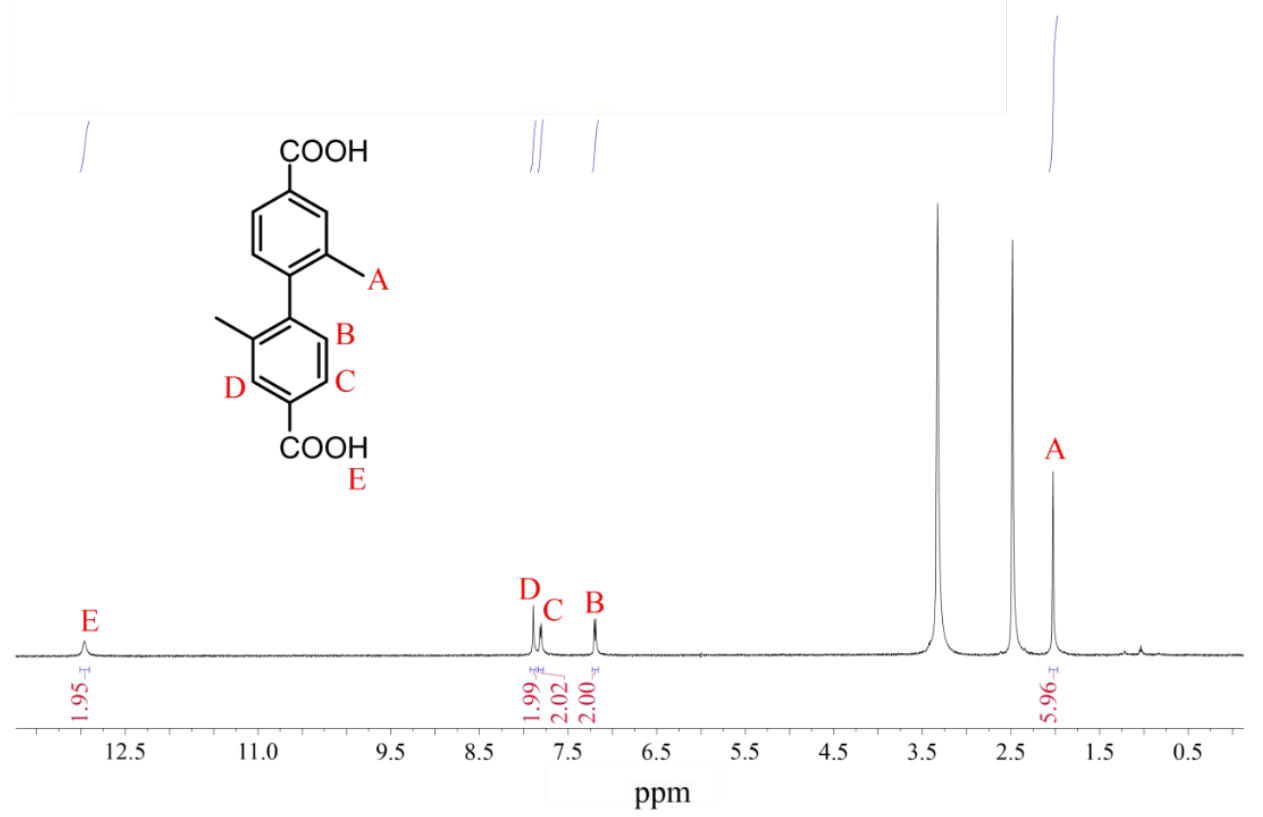

Figure S12. ${ }^{1} \mathrm{H}$ NMR spectrum of digested PCN-700 in DMSO- $d_{6}$. The resonances are corresponding to $\mathrm{Me}_{2}-\mathrm{BPDC}$. 


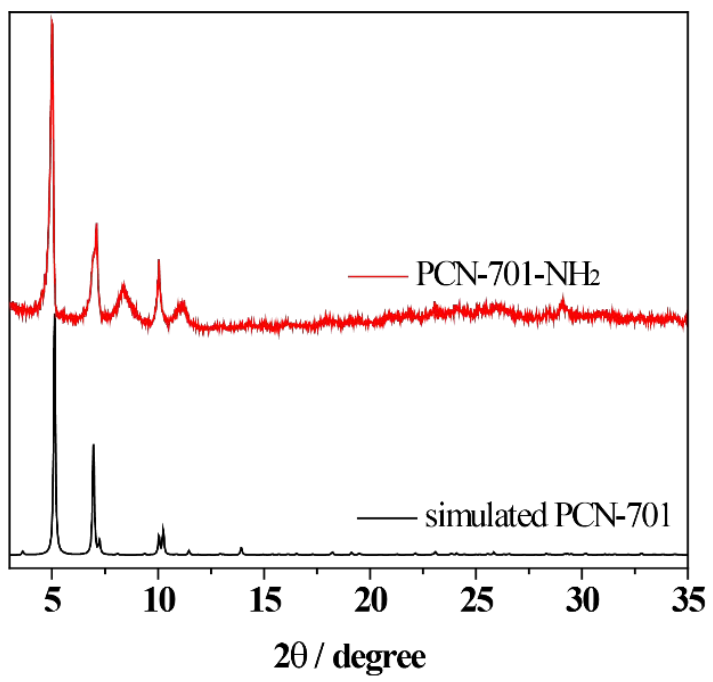

Figure S13. The PXRD patterns of simulated PCN-701 and as-synthesized PCN-701-NH $\mathrm{NH}_{2}$ 


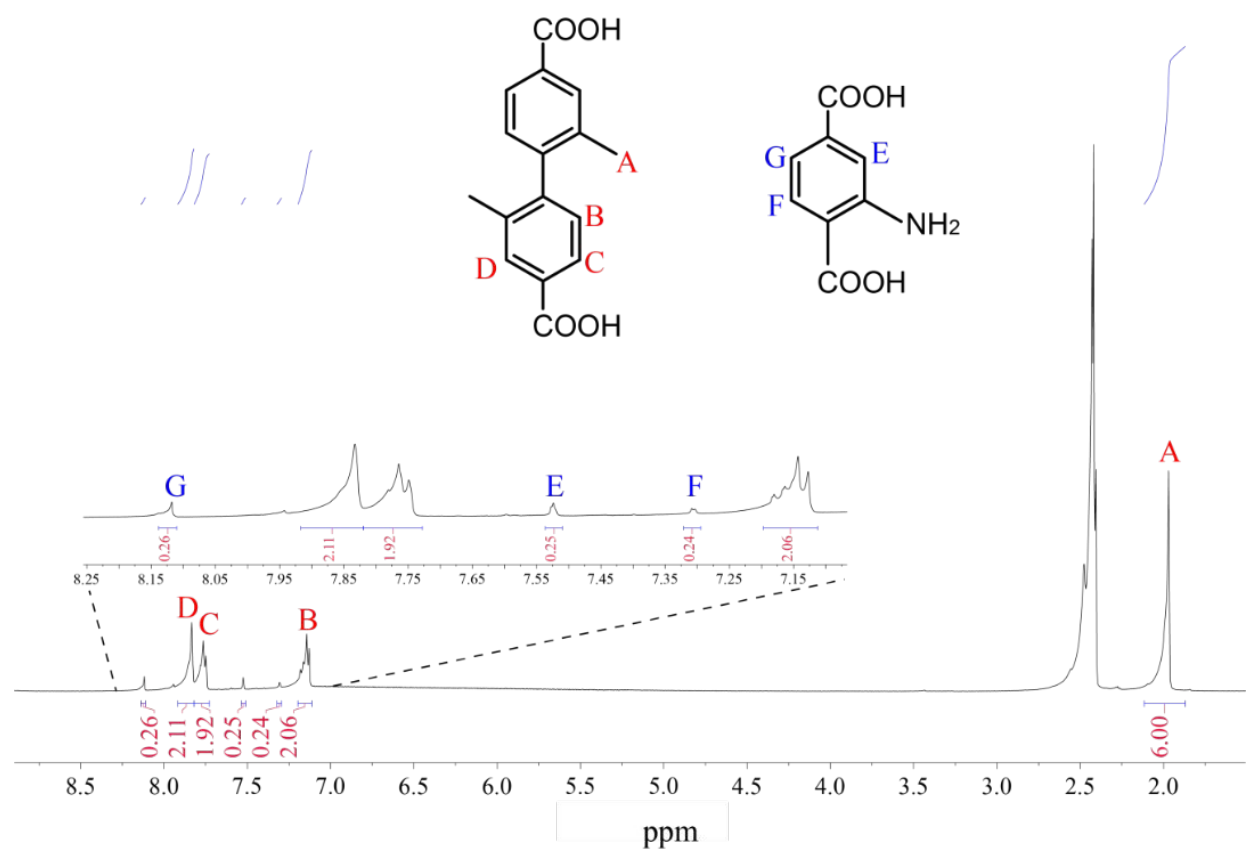

Figure S14. ${ }^{1} \mathrm{H}$ NMR spectrum of digested PCN-701-NH 2 in DMSO- $d_{6}$. The resonances are corresponding to $\mathrm{Me}_{2}-\mathrm{BPDC}$ and $\mathrm{NH}_{2}-\mathrm{BDC}$. The molar ratio of $\mathrm{Me}_{2}-\mathrm{BPDC}$ and $\mathrm{NH}_{2}-\mathrm{BDC}$ is $(2.06+1.92+2.11) / 6:(0.24+0.25+0.26) / 3 \approx 4$. 


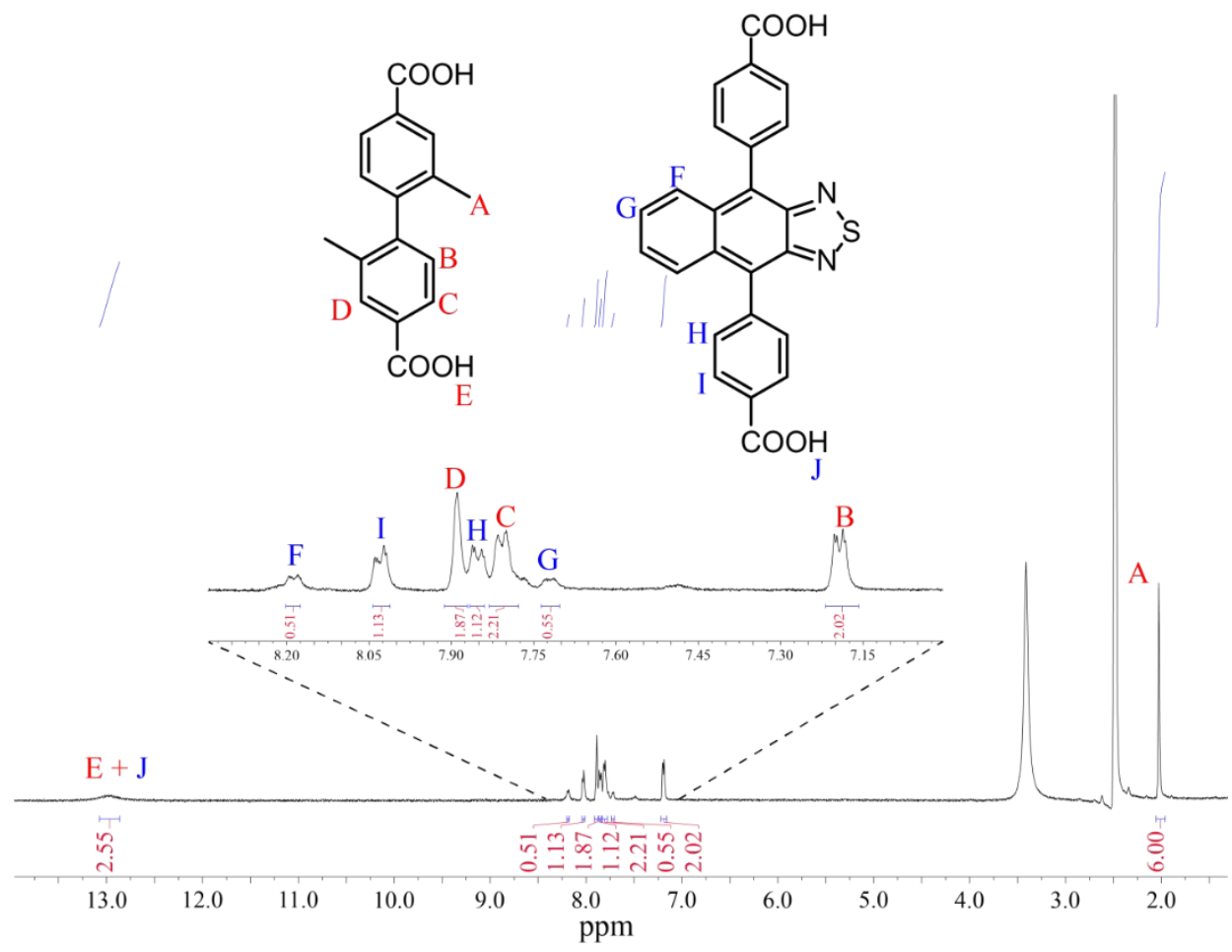

Figure S15. ${ }^{1} \mathrm{H}$ NMR spectrum of digested PCN-702-NTB in DMSO- $d_{6}$. The resonances are corresponding to $\mathrm{Me}_{2}-\mathrm{BPDC}$ and NTB. The molar ratio of $\mathrm{Me}_{2}-\mathrm{BPDC}$ and $\mathrm{NTB}$ is $(2.02+2.21+1.87) / 6:(0.55+1.12+1.13+0.51) / 12 \approx 4$. 


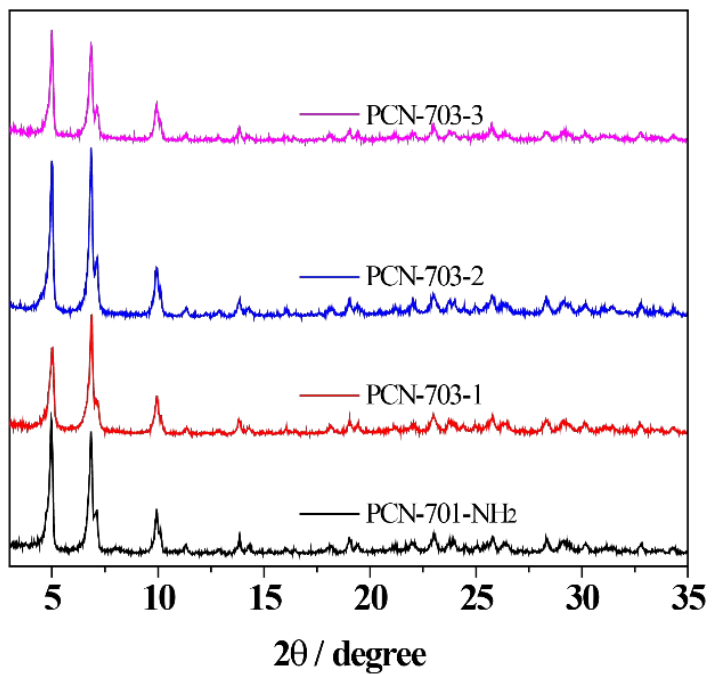

Figure S16. The PXRD patterns of simulated PCN-703 and as-synthesized PCN-703- $\mathrm{NH}_{2}-$ NTDB with different installation concentration of NTB. 


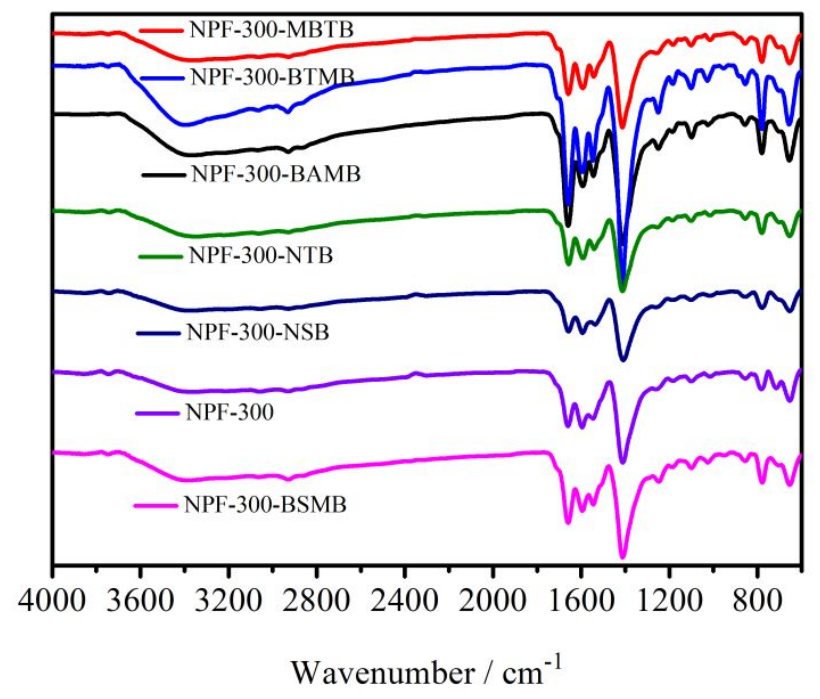

Figure S17. FTIR spectra of NPF-300, NPF-300-BAMB, NPF-300-MBTB, NPF-300-BTMB, NPF-300-BSMB, NPF-300-NTB and NPF-300-NSB. 


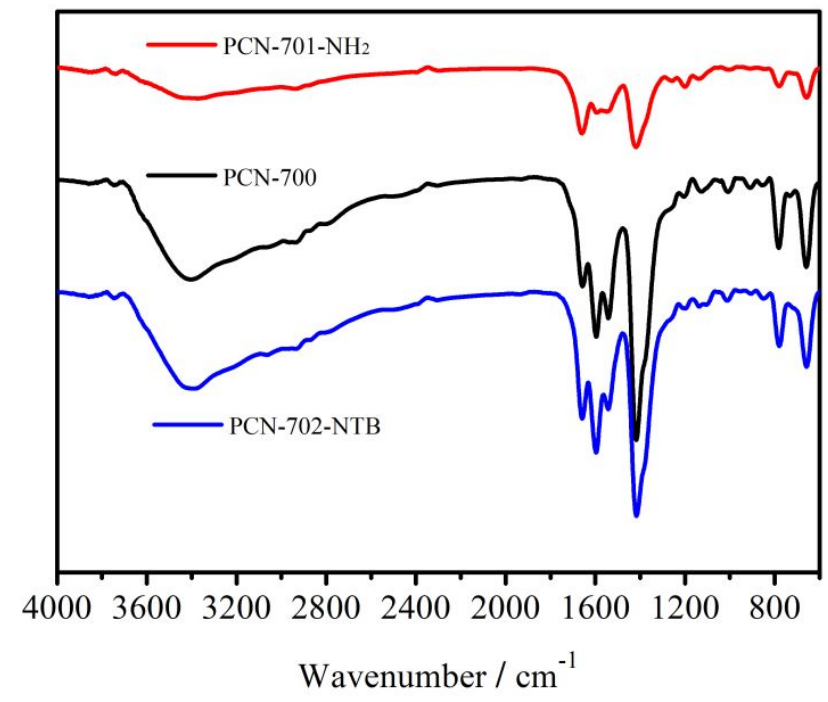

Figure S18. FTIR spectra of PCN-700, PCN-701-NH 2 and PCN-702-NTB. 
Table S1. Crystal data and structure refinement for NPF-300-MBTB.

CCDC No.

Empirical formula

Formula weight

Temperature

Wavelength

Crystal system

Space group

Unit cell dimensions

Volume

Z

Density (calculated)

Absorption coefficient

$\mathrm{F}(000)$

Crystal size

Theta range for data collection

Index ranges

Reflections collected

Independent reflections

Data / restraints / parameters

Goodness-of-fit on $\mathrm{F}^{2}$

Final R indices [I $>2 \operatorname{sigma}(\mathrm{I})]$

$\mathrm{R}$ indices (all data)

Largest diff. peak and hole
2109845

C48.45H25.06N0.38O16S0.19Zr3

1148.23

$270 \mathrm{~K}$

$1.54178 \AA$

orthorhombic

Immm

$$
\begin{array}{ll}
\mathrm{a}=23.3679(4) \AA & \mathrm{a}=90^{\circ} \\
\mathrm{b}=33.2599(6) \AA & \mathrm{b}=90^{\circ} \\
\mathrm{c}=41.0289(9) \AA & \mathrm{c}=90^{\circ}
\end{array}
$$

$31888.2(11) \AA^{3}$

8

$0.478 \mathrm{~g} / \mathrm{cm}^{3}$

$1.785 \mathrm{~mm}^{-1}$

4556.0

$0.35 \times 0.13 \times 0.1 \mathrm{~mm}^{3}$

6.87 to $144.602^{\circ}$

$-28<=\mathrm{h}<=28,-37<=\mathrm{k}<=41,-42<=\mathrm{l}<=50$

66141

$16519[\mathrm{R}(\mathrm{int})=0.0375, \mathrm{R}($ sigma $)=0.0360]$

$16519 / 267 / 381$

1.109

$\mathrm{R} 1=0.0527, \mathrm{wR} 2=0.1716$

$\mathrm{R} 1=0.0561, \mathrm{wR} 2=0.1762$

1.75 and -1.42 e. $\AA^{-3}$ 


\section{References}

1. S. Wu, D. Ren, K. Zhou, H.-L. Xia, X.-Y. Liu, X. Wang and J. Li, Linker Engineering toward Full-Color Emission of UiO-68 Type Metal-Organic Frameworks. J. Am. Chem. Soc., 2021, 143, 10547-10552.

2. D. Ren, H.-L. Xia, K. Zhou, S. Wu, X.-Y. Liu, X. Wang and J. Li, uning and Directing Energy Transfer in the Whole Visible Spectrum through Linker Installation. Angew. Chem. Int. Ed., 2021, 60, doi.org/10.1002/anie.202110531.

3. X. Zhang, B. L. Frey, Y. S. Chen and J. Zhang, Topology-Guided Stepwise Insertion of Three Secondary Linkers in Zirconium Metal-Organic Frameworks. J. Am. Chem. Soc., 2018, 140, 7710-7715.

4. S. Yuan, W. Lu, Y. P. Chen, Q. Zhang, T. F. Liu, D. Feng, X. Wang, J. Qin and H. C. Zhou, Sequential linker installation: precise placement of functional groups in multivariate metal-organic frameworks. $J$. Am. Chem. Soc., 2015, 137, 3177-3180.

5. O. V. Dolomanov, L. J. Bourhis, R. J. Gildea, J. A. K. Howard and H. Puschmann, OLEX2: a complete structure solution, refinement and analysis program. J. Appl. Cryst., 2009, 42, 339-341.

6. G. Sheldrick, SHELXT-Integrated space-group and crystal-structure determination. Acta Cryst., 2015, A71, 3-8.

7. G. Sheldrick, Crystal structure refinement with SHELXL. Acta Cryst., 2015, C71, 3-8. 